\title{
The Alkaline Solution to the Emergence of Life: Energy, Entropy and Early Evolution
}

\author{
Michael J. Russell
}

Published online: 4 December 2007

(C) Springer Science+Business Media B.V. 2007

\section{Erratum to: Acta Biotheor 55: 133-179 (2007) DOI 10.1007/s10441-007-9018-5}

All figures in this article are not correct. In the following pages, you will find the right figures which should be seen as definitive.

The online version of the original article can be found under doi:10.1007/s10441-007-9018-5. 


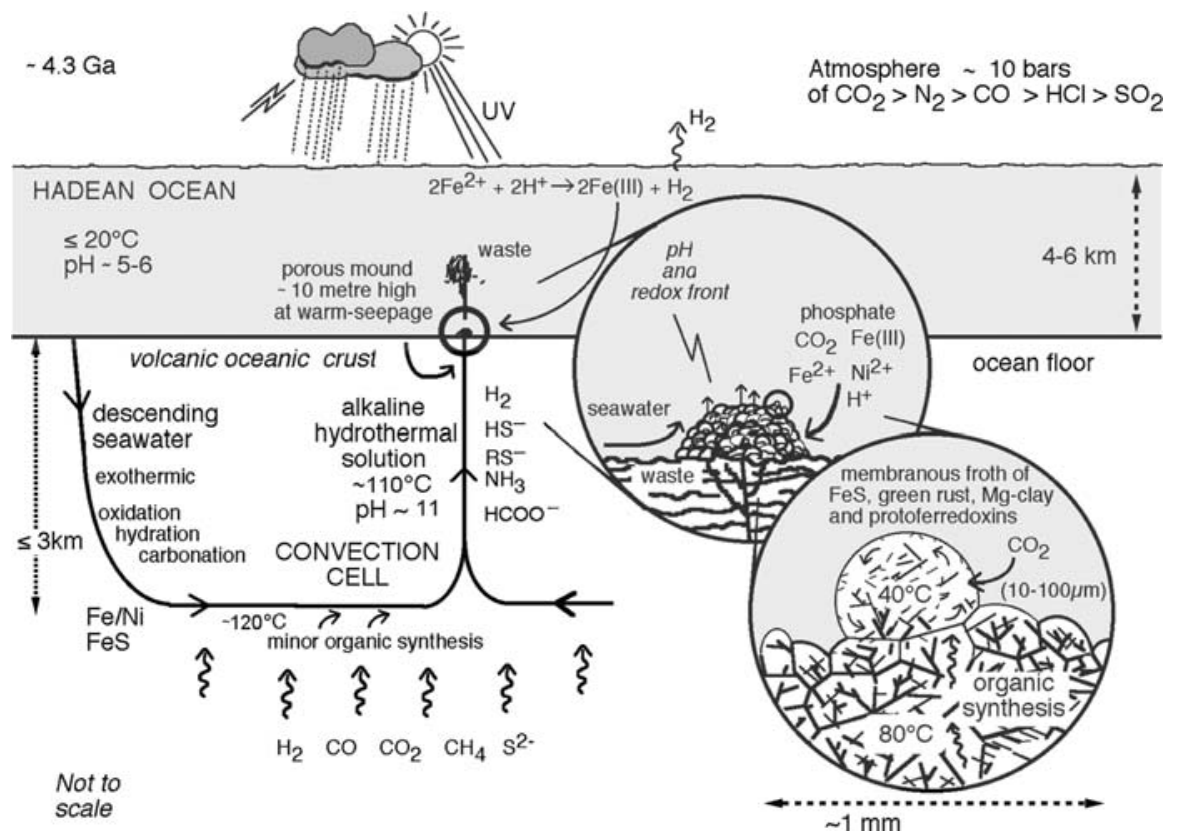

Fig. 1 Model environment for the emergence of life at a submarine seepage on the ocean floor. It is at an alkaline submarine spring that the chemical and electrochemical energy is a maximum in the aqueous conditions required by life-here that this energy is discharged (after Russell and Hall 2006) 


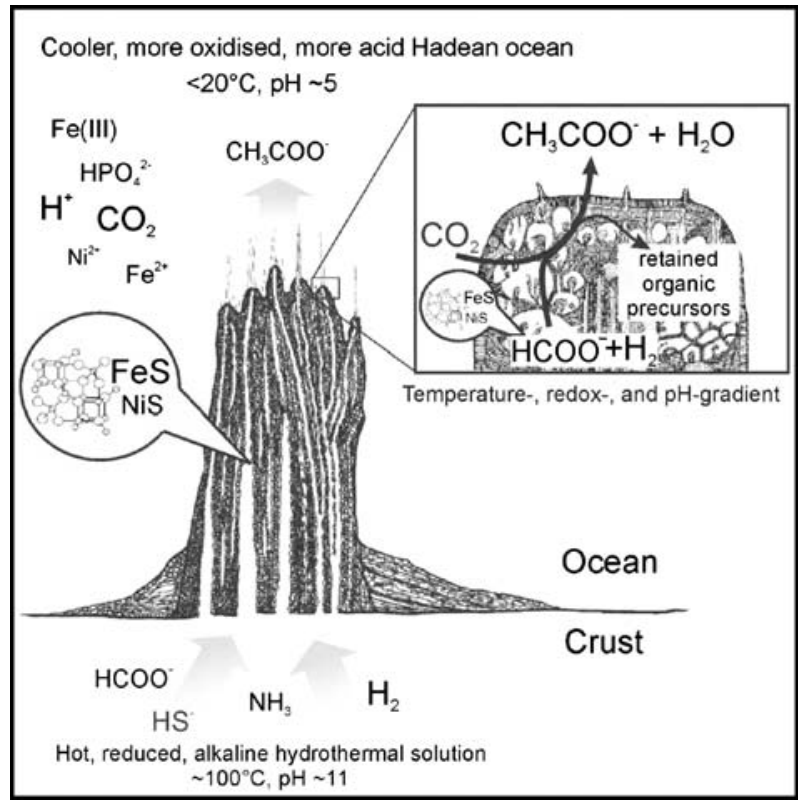

Fig. 2 The hydrothermal mound sketched as an acetate (or methane) generator. The detailed crosssection of the surface illustrates the sites where organic ions are produced, retained, react and selforganize to emerge as protolife (recast from Russell and Martin 2004). Though alkaline springs with abundant soluble sulfide may have been rare, there would have been many thousands of them operating over millions of years, and the ones with the highest sulfide content are those that are most likely to have given rise to life, i.e., where chemical and electrochemical energies were best discharged (cf., Smith and Morowitz 2006)

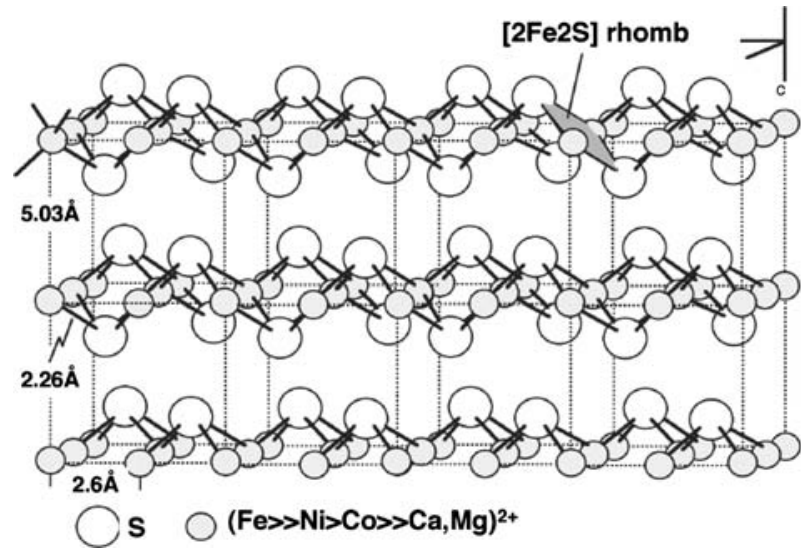

Fig. 3 Structure of mackinawite $\mathrm{FeS}$. Mackinawite consists of an assemblage of [2Fe2S] rhombs (Wolthers et al. 2003) arranged in such a way that it acts as an insulator through the $c$-axis and a semiconductor in the $b c$-plane (Ferris et al. 1992). As such it may have acted as the first electron transfer agent through the membrane (after Russell and Hall 1997; Russell et al. 1998) 
(b) thiocubane (in ferredoxin)
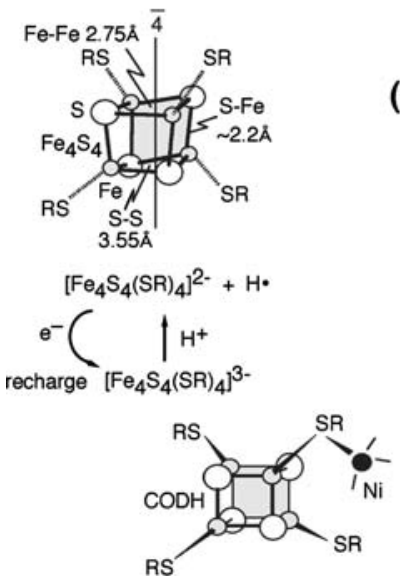

(c) $\mathrm{CODH}-\mathrm{C}$ cluster CO-dehydrogenase (Rhodospirillum sp.)

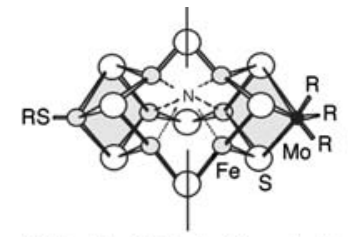

(a) greigite $\mathrm{Fe}_{5} \mathrm{NiS}_{8}$ (sulfospinel) half unit cell

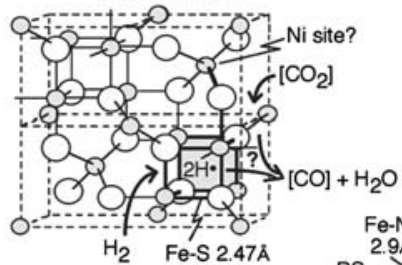

(f) FeMo cofactor of nitrogen-fixing enzyme (nitrogenase)

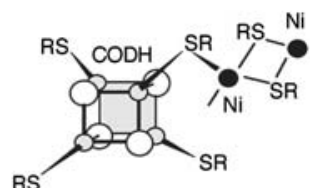

(e) $\mathrm{CODH}-\mathrm{A}$ cluster CO-dehydrogenase

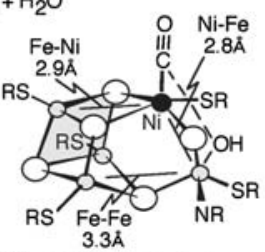

(d) $\mathrm{CODH}-\mathrm{C}$ cluster CO-dehydrogenase (Carboxydothermus sp.)

Fig. 4 Structural relatedness of: (a) greigite $\mathrm{Fe}_{5} \mathrm{NiS}_{8}$; (b) the thiocubane $\left[\mathrm{Fe}_{4} \mathrm{~S}_{4}\right]$ unit in protoferredoxins and ferredoxins; (c, d and e) the $\left[\mathrm{Fe}_{4} \mathrm{NiS}_{5}\right]$ open cuboidal complexes in $\mathrm{CO}$-dehydrogenase; (f) the twinned centre to nitrogenase. Affine sulfur sub-lattices, cubic close-packed in (a), are distorted in the metalloenzyme centres. The presence or absence of $\mathrm{Fe}^{\mathrm{III} / 3+}$, Mo, $\mathrm{Ni}$ and organic ligands may dictate which of these entities formed in the first cells. After Russell and Hall (1997, 2006), Russell et al. (1998), Dobbeck et al. (2001), Drennan et al. (2001), Doukov et al. (2002), Einsle et al. (2002), Svetlitchnyi et al. (2004), Russell and Martin (2004) 


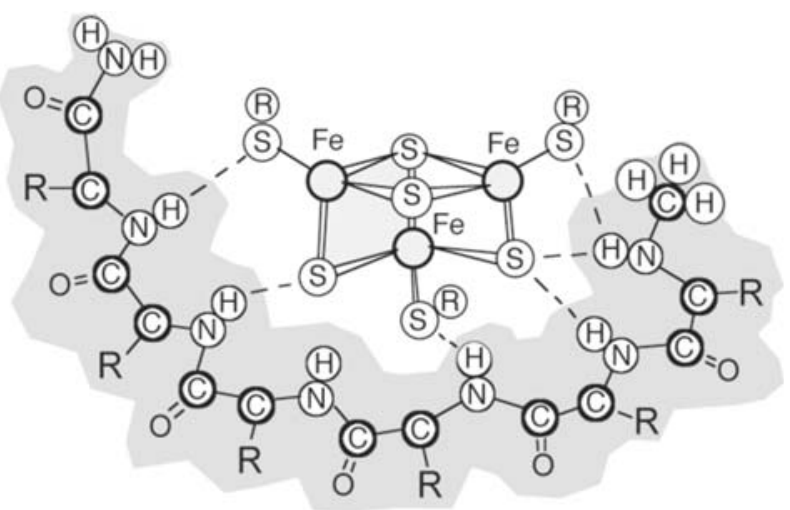

(a) $\mathrm{Fe}_{3} \mathrm{~S}_{4}$ in peptide nest

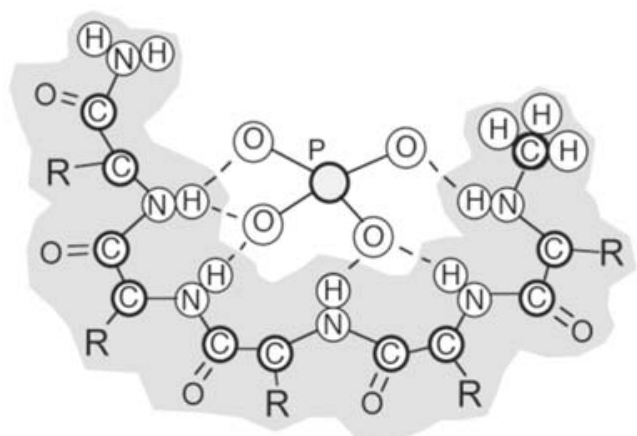

(b) Phosphate in peptide nest

Fig. 5 Ball and stick sketches of compound early 'nests' of peptides comprised of $\alpha$-chain backbones of racemic abiotic amino acids binding: (a) an inorganic phosphate 'egg' (b) a putative protoferredoxin anionic 'egg' or active centre such as $\left[\mathrm{Fe}_{3} \mathrm{~S}_{4}\right](\mathrm{RS})_{3}^{-}$. A typical 5-mer sequence might be D-alanine, L-alanine, glycine. D-alanine, methylated L-alanine. After Milner-White and Russell (2005) 

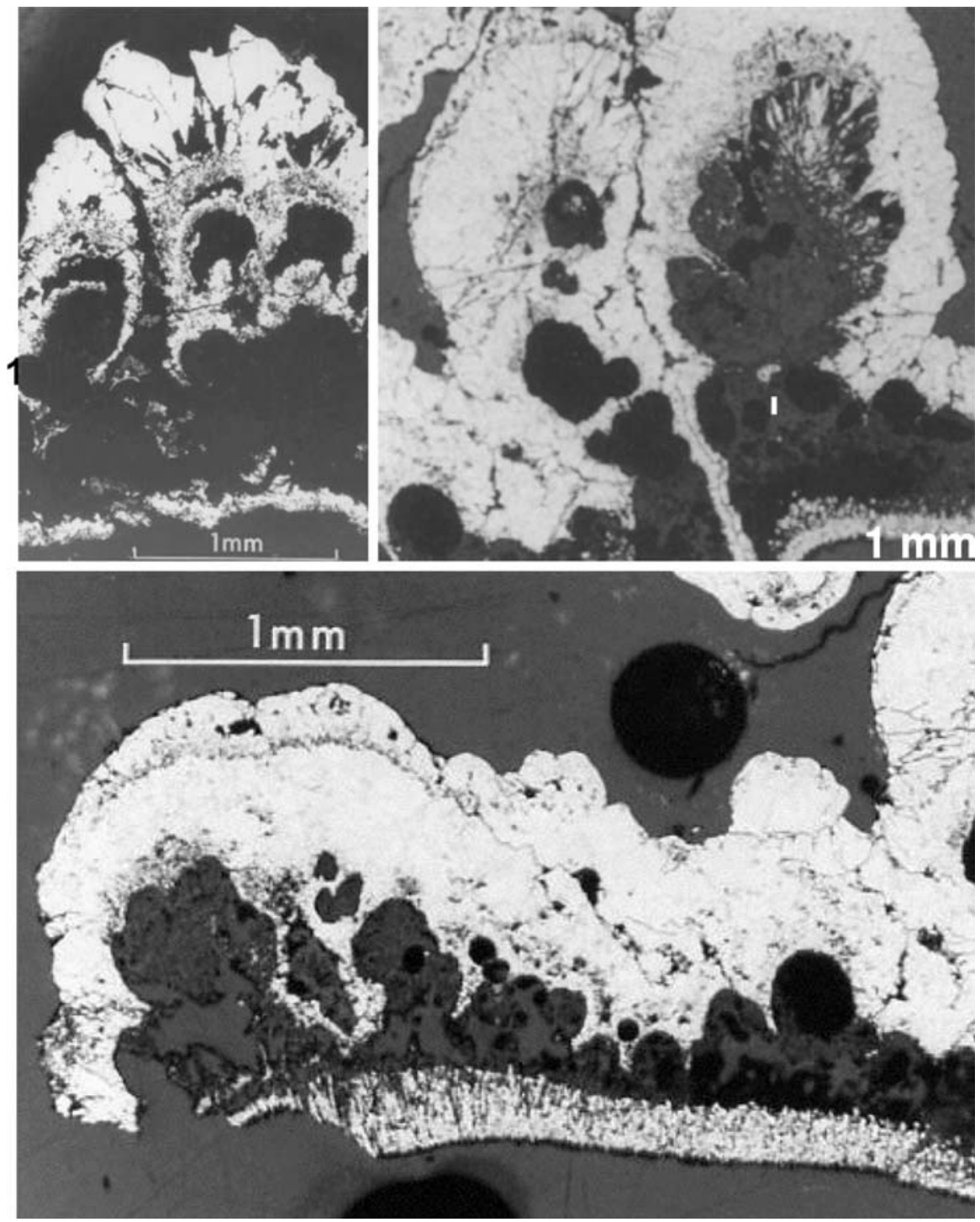

Fig. 6 Polished cross-sections of the Tynagh iron sulfide botryoids. These structures inspired the idea that the first compartments involved in the emergence of life were of comparable structure. It should be noted that the sulfide comprising what is now pyrite $\left(\mathrm{FeS}_{2}\right)$ in these 350 million year old submarine deposits was derived through bacterial sulfate reduction that took place in somewhat alkaline and saline seawater while the iron was contributed by exhaling acidic hydothermal solutions. On the early Earth the sulfide would have been carried in the alkaline solution as bisulfide, whereas the iron would have been contributed from the acidulous Hadean Ocean. On mixing, mackinawite $(\mathrm{Fe}(\mathrm{Ni}) \mathrm{S})$ and greigite $\left(\mathrm{Fe}_{5} \mathrm{NiS}_{8}\right)$ would have precipitated to form inorganic membranes at the interface (Russell et al. 1994; Russell and Hall 1997). Submarine mounds are invariably porous (Marteinsson et al. 2001; Kelley et al. 2005) 